\title{
The Role of University Students' General Self-Efficacy, Depression and Psychological Well-being in Predicting Their Exercise Behavior
}

\author{
Gözde Ersöz \\ Correspondence: Gözde Ersöz, Department of Physical Education and Sport Teaching, Namık Kemal University, \\ Tekirdag, Turkey.
}

Received: November 29, 2016

doi:10.11114/jets.v5i3.2209

\author{
Accepted: February 2, $2017 \quad$ Online Published: February 8, 2017 \\ URL: http://dx.doi.org/10.11114/jets.v5i3.2209
}

\begin{abstract}
The aim of this research is to examine the relationship between exercise and general self-efficacy, depression, and psychological well-being of college students. Five hundred and twenty-two university students $\left(n_{\text {male }} 273 ; X_{\text {age }}=\right.$ $23.33 \pm 4.36$ and $\left.n_{\text {female }}=279 ; X_{\text {age }}=25.91 \pm 7.11\right)$ have participated in this research. The General Self-Efficacy Scale (GSES), Beck Depression Inventory (BDI), Physical Activity Stages of Change Questionnaire (PASCQ), and "Psychological Well-Being Scale (PWBS) have been applied to the sample group in this study. While differences in participants' self-efficacy, depression, and psychological well-being levels with regard to the stage of changes in exercise are calculated with one way analysis of variance (ANOVA), the relationship between these ideas discussed in the research have been determined with Pearson Moments Product Correlation Analysis. According to the stages of exercise behavior, significant disparities have been found between participants' level of self-efficacy, depression, and psychological well-being, and the relationship between those notions has been observed. According to the results, the participants' general self-efficacy and psychological well-being levels were high and the depression levels were low when on advanced levels of exercise. In light of the findings obtained from this research, it has been concluded that continuity in exercise has a positive effect on psychological effects like general self-efficacy, depression and psychological well-being.
\end{abstract}

Keywords: general self-efficacy, depression, psychological well-being, stage of change in exercise, trans-theoretical model

\section{Introduction}

World health authorities have accepted the theory that regular physical activity is the basis of a healthy life (World Health Organization, 1995). Exercise has many psychological benefits on emotional processes like stress and depression, and physiological processes like heart diseases, hypertension, diabetes, and obesity (U.S. Department of Health and Human Service, 1996). Even though this positive relationship between exercise and health is known, most people prefer an inactive lifestyle (Georgiadis, Biddle \& Chatzisarantis, 2001). For example, according to a study conducted in England, $72 \%$ of English, 69\% of Irish, and 69\% of Scottish people are not physically active. Similarly, according to statistics from health scans conducted in Canada, $47.8 \%$ of the population is identified as inactive during leisure time (Lowther, Mutrie \& Scott, 2007). An extensive study with the participation of 23 countries by Haase, Steptoe, Sallis and Wardle (2004) revealed that college students do not engage in physical activities at recommended levels. In addition, a study conducted on 1,097 college students by Savc1 et al. (2006) in Turkey found that students' activeness levels are low.

There has been an increase in studies that focus on researching the psychological processes of those who do not exercise or think about exercising (Rodgers, Hall, Duncan, Pearson, \& Milne, 2010). The results of these studies in the very vast field of exercise have been added to our knowledge related to psychological processes (Thøgersen-Ntoumani \& Ntoumanis, 2006; Maiolino \& Kuiper, 2016). Studies on exercise behavior are usually conducted with participants who continue to exercise, while studies that focus on psychological factors during this habit are extremely rare (Rodgers et al., 2010).

In this way, several models have been revealed that attempt to explain exercise behavior processes (Spencer, Adams, Malone, Roy, \& Yost, 2006). For example, the Trans-theoretical Model has been frequently applied and explains differences in a person's health behavior with the stage of changes paradigm (Prochaska \& DiClemente, 1984). The 
Trans-theoretical Model has been used to explain many health behaviors, like nutritional, addictive drug, and smoking habits before focusing on a person's exercise behavior (Adams \& White, 2002; Marshall \& Biddle, 2001; Spencer et al., 2006). This model focuses on situations in which individuals desire behavior modification, and then help the person realize this change, understand the modification process, and identify the procedure of developing this habit as a gradual, continuous, and dynamic structure. This model defends the perspective that an individual does not directly travel from old problematic behavior (not exercising) to new behavior (exercising), but rather does so through a gradual series (Burbank, Reibe, \& Padula, 2002). Change begins with a person realizing the behavior is unhealthy and continues until the problematic habits change over time and new positive behavior becomes adopted in accordance with the individual's desires (Marshall \& Biddle, 2001). The Trans-theoretical Model has been used for the purposes of physical activity and modification of behavior in exercise, implying that this model could be beneficial in this field (Cengiz, Aşçı, \& İnce, 2010; Prochaska \& Velicer, 1997). Studies support that research on understanding exercise behavior that is grounded in the Trans-theoretical Model is beneficial (Purath, Miller, McCabe, \& Wilbur, 2004; Woods, Mutrie, \& Scontt, 2002).

Research that attempts to understand the mechanisms underlying exercise and health behavior usually apply a social cognitive model (Bandura, 1977). One of the factors most researched in this model is general self-efficacy, identified as the belief in one's abilities that allows a person to manage situations expected of him or her (Luszczynska, Gutiérrez Doña, \& Schwarzer, 2005). Since exercising requires personal characteristics like exertion, effort, and patience, general self-efficacy has an effect on this behavior (McAuley \& Blissmer, 2000). Research in the field of exercise psychology that runs parallel to this belief revealed that general self-efficacy is effective on participating in exercise (McAuley, 1992), weight control (Bernier \& Avard, 1986), and improving health-related behavior (O'Leary, 1992). For example, McAuley and Jacobson (1991) found that once female participants exercised after a sedentary period, general self-efficacy was related to commitment to the exercise and exercise duration. McAuley, Lox and Duncan (1993) reported that general self-efficacy predicts exercise continuity in adults.

One of the psychological notions in this research is depression, an emotional situation that negatively affects the quality of life of millions around the world (Gelenberg, 2010). Pharmacotherapy and psychological interventions has been used in the past in order to treat depression. However, recent studies revealed that exercise reduces depression symptoms with the help of traditional treatments (Antunes, Stella, Santos, Bueno, \& Mello., 2005; Singh, Clements, \& Singh, 2001; Callaghan, Khalil, Morres, \& Carter., 2011). Former studies indicated that exercise has the same effect as medication (Brenes et al., 2007; Blumenthal et al., 2007) or psychological interventions (Fremont \& Craighead, 1987). The National Service Framework for Mental Health (NICE) suggested for individuals to incorporate exercise while undergoing depression treatment during the process (Donaghy \& Durward, 2000). According to the NICE depression guide, mild exercise performed with a consultant three times a week (45 minutes-1 hour) for 10-14 weeks regulates symptoms of depression (NICE, 2009). According to another guide published by the Scottish Intercollegiate Guidelines Network (SIGN), exercise can help adults cope with depression without the need to take medication (Network, 2002). An exercise guidance system has been established in England (DOH, 2001) and support has been provided for those who want to receive assistance with exercising, but after general assessment, not enough evidence has been found to defend the efficiency of this system and no recommendations have been made for future studies (Sorensen, Skovgaard, \& Puggaard, 2006).

Another subject related to exercise is psychological well-being. Muraven and Baumeister (2000) assert that individuals have a limited amount of energy to alter their behavior, and mental stress might reduce this energy. Depressed or stressed individuals may have problems completing an exercise program, and this situation negatively affects their psychological situation (Jones, Harris, Waller, \& Coggins, 2005). The relationship between psychological well-being and physical activity is supported by previous studies (Sebire, Standage, \& Vansteenkiste, 2009; Sebire, Standage, \& Vansteenkiste, 2011).

This study is important to perspectives on community health care since encouraging individuals to increase physical activities, including regular and medium level exercise, in their daily routines and contributing to this effort signifies support of community health care. In addition, this result of this study will expand knowledge related to the effects of attempts to alter physical activity based on a stage of change model regarding psychological notions like general self-efficacy, depression, and psychological well-being. This study's aim is to examine the relationship between exercise behavior and the general self-efficacy, depression, and psychological well-being of university students. Based on the extant research, we hypothesised that: (1) general self-efficacy and psychological well-being would be positively associated with the stages of exercise behavior; (2) Depression would be negatively associated with the stages of exercise behavior; (3) general self-efficacy would be higher in later stages of change; (4) depression would be higher in earlier stages of change; (5) psychological well-being would be higher in later stages of change. 


\section{Methods}

\subsection{Participants}

The study sample consist of $279(\% 51)$ female, $273(\% 49)$ male for a total of 552 (Xage $=24.63 \pm 6.05)$ university students who age ranged 17 to 30 years old. All participants participated to the study voluntarily. Prior to the study, approval to conduct research with human participants was obtained from the university's ethical committee. All participants provided signed an informed consent before taking part in the study.

\subsection{Instruments}

"General Self-Efficacy Scale (GSES)", "Beck Depression Inventory (BDI)", "Psychological Well-Being Scale (PWBS)" and "Physical Activity Stages of Change Questionnaire (PASCQ)" were administered to all participants. The details of each questionnaire were given below:

\subsubsection{General Self-efficacy Scale (GSES)}

The self-efficacy level of participants was measured by a 17-item scale which is originally developed by Sherer and Adams (1983) and adapted to Turkish by Yildirım and İlhan (2010). The participants were asked to answer the question of "How much do the following statements describe you?" based on a 5-point Likert scale ranging from 1-"Strongly not describe" to 5-"Strongly describe". The scale has a three-factor structure to measure the various aspects of self-efficacy, including initiation, effort, and persistence. Sample questions include: "When I make plans, I am certain I can make them work", "I give up easily", "I am a self-reliant person", and "I avoid facing difficulties". The total score reflects the level of self-perceived general self-efficacy. Eleven out of 17 items in the scale are reverse coded. The total scale score ranges from 17 to 85. Any increase in a participant's total score indicates the increase in his/her general self-efficacy level (Sherer \& Adams, 1983). In the adaptation study of the scale into Turkish, the Cronbach's alpha internal consistency coefficient, Guttman split-half coefficient, and Pearson correlation coefficient for test-retest reliability were found to be $0.80,0.77$, and 0.69 respectively (Ylldırm \& İlhan, 2010), indicating high reliabilities. In this study, Cronbach's alpha was calculated as 0.85 .

\subsubsection{Beck Depression Inventory (BDI)}

The BDI is a 21-item self-report inventory designed to assess the behavioral and cognitive symptoms of depression (Beck \& Steer, 1987). Each item consists of several statements describing symptoms of depression. Participants were asked to circle the statement that best described their symptoms related to that particular aspect of depression (i.e. feelings of guilt, changes in sleep). The statements are numbered from " 0 " to " 3 ", with higher numbers indicating more severe symptoms. Scores for responses are summed to obtain an overall score. The overall sum can range from 0 to 63 , with higher scores indicating more severe depression. This inventory has demonstrated acceptable internal consistency with the authors reporting Cronbach's alphas ranging from 0.92 to 0.93 (Beck \& Steer, 1987). The cut-off score for validity and reliability in the Turkish version of the scale is 17 . The scale was adapted for Turkish populations by Hisli et al. (1989). Internal consistency for this study was examined using Cronbach's alpha and was deemed acceptable with $\alpha=0.91$.

\subsubsection{Psychological Well-being Scale (PWBS)}

The eight-item PWBS was identified to positive relationship, feeling competencies and having meaningful and purposeful life. İt was developed by Diener et al. (2010) and The Turkish adaptation of the scale has been done by Telef (2013). The response scale was a 7-point likert-type scale ranging from 1 (I don't agree at all) to 7 (I completely agree).The researcher has determined as a result of descriptive factor analysis that the single dimensional structure explains 53\% of the variance. The factor loadings of the scale were changing between 0.61 to 0.77 . The internal consistency coefficient of the orijinal scale was 0.87. In the present study, Cronbach's alphas of the scale was 0.85.

\subsubsection{Physical Activity Stages of Change Questionnaire (PASCQ)}

The PASCQ consists of 4-items and it assesses individuals' level of readiness to attend exercise (Marcus \& Lewis, 2003). The questionnaire group individuals into 1 of the 5 stages of exercise behavior (pre-contemplation, contemplation, preparation, action, and maintenance) by using a scoring algorithm. It is a binary type (yes/no) questionnaire. Participants in the pre-contemplation stage are inactive and have no intention to become active over the next 6 months. In the contemplation stage, people are inactive but plan to begin exercising within the next 6 months. The preparation stage includes individuals who exercise sometimes but not regularly. Individuals in the action stage have been exercising regularly less than 6 months. Individuals in the maintenance stage have been exercising regularly 6 months or longer. We used the Turkish version, which was previously validated among Turkish college students and demonstrated good psychometric properties (Cengiz, Aşç1, \& İnce, 2010). 


\subsection{Data Analysis}

Data obtained on the research were transferred to SPSS 18.0 program. Data were tested for normal distribution and homogeneity of variance using Kolmogorov-Smirnov and Levene's test before statistical procedures were applied. To determine the relationships among the means of general self-efficacy, psychological well-being and depression scores Pearson Moment of Correlation analysis method was used. ANOVA was used to analysis the differences of general self-efficacy, psychological well-being and depression scores in terms of stage of changes in exercise. If in ANOVA analysis was found a difference, post hoc Tukey's test was used for analysis for the difference between groups. Statistical significance level was considered as $\mathrm{p}<0.05$.

\section{Results}

Table 1. Means and Standard Deviations for general self-efficacy, depression and psychological well-being scores of participants

\begin{tabular}{llll}
\hline & Female $(\mathbf{n = 2 7 9})$ & Male $(\mathbf{n = 2 7 3})$ & $\begin{array}{l}\text { Total participants }(\mathbf{n = 5 5 2}) \\
\text { Variables }\end{array}$ \\
\hline G $\boldsymbol{S} \boldsymbol{D}$ & $45.77 \pm 16.57$ & $47.59 \pm 15.29$ & $46.67 \pm 15.96$ \\
Deneral self-efficacy & $18.66 \pm 12.25$ & $15.10 \pm 11.98$ & $16.92 \pm 12.24$ \\
Psychological well-being & $34.74 \pm 16.80$ & $38.85 \pm 15.43$ & $36.77 \pm 16.26$ \\
\hline
\end{tabular}

Means and standard deviation of general self-efficacy, depression and psychological well-being scores of participants are shown in Table 1.

Table 2. Correlation Coefficients between General Self-Efficacy, Depression And Psychological Well-Being

\begin{tabular}{clc}
\hline & & Stage of Change in Exercise \\
$\mathbf{1}$ & General self-efficacy & $.17^{* *}$ \\
\hline $\mathbf{2}$ & Depression & $-.26^{* *}$ \\
$\mathbf{3}$ & Psychological well-being & $.19^{* * *}$ \\
$* *: \mathrm{p}<0.01$ &
\end{tabular}

Pearson correlations between general self-efficacy, depression and psychological well-being findings are presented in Table 2. As is seen on the Table 2, there is a positive small relationship between general self-efficacy $(r=.17, p<0.01)$, psychological well-being $(r=.19, p<0.01)$ and stage of change in exercise. In contrast, there is a negative small relationship between depression $(r=-.26, p<0.01)$ and stage of change in exercise. These findings provided support for the first and second hypotheses.

Table 3. Mean Differences Among the Stages of Change in General Self-Efficacy, Depression And Psychological Well-Being

\begin{tabular}{|c|c|c|c|c|c|c|c|c|c|c|c|c|}
\hline & $\begin{array}{l}\text { Stage o } \\
\text { Pre-Co } \\
(n=103 \\
\end{array}$ & $\begin{array}{l}\text { Chang } \\
\text { templa }\end{array}$ & $\begin{array}{ll} & \\
\text { in Exe } \\
\text { on } & C \\
& (n \\
\end{array}$ & $\begin{array}{l}\text { ercise } \\
\text { Contemplation } \\
n=124)\end{array}$ & $\begin{array}{r}\text { Pr } \\
(n=11\end{array}$ & $\begin{array}{l}\text { eparation } \\
\text { 5) }\end{array}$ & $\begin{array}{l}\text { Action } \\
(\mathbf{n}=70)\end{array}$ & & $\begin{array}{l}\text { Maint } \\
(n=14\end{array}$ & nance & & \\
\hline & $M$ & $S D$ & $M$ & $S D$ & $M$ & $S D$ & $M$ & $S D$ & $M$ & $S D$ & $F$ & $p$ \\
\hline General self-efficacy & 27.59 & 1.42 & 33.86 & $5 \quad 1.30$ & 32.90 & 1.35 & 48.91 & 1.72 & 51.44 & 1.22 & 59.46 & $<.001 * * *$ \\
\hline Depression & 22.26 & 1.08 & 23.52 & 20.99 & 12.41 & 1.02 & 15.01 & 1.31 & 12.63 & 0.93 & 28.05 & $<.001 * * *$ \\
\hline Psychological well-being & 15.17 & 1.95 & 22.06 & $\begin{array}{ll}5 & 1.78 \\
\end{array}$ & 26.73 & 1.82 & 20.23 & 2.33 & 22.80 & 1.65 & 5.03 & $<.01 * *$ \\
\hline
\end{tabular}

$* * \mathrm{p}<0.01 * * * \mathrm{p}<0.001$

A significant difference for stage of change in exercise was observed in a ANOVA with general self-efficacy as the dependent variables $\left(F_{(4,547)}=59.46, p<0.001\right)$. Tukey's post hoc tests indicated that participants in the maintenance stage reported higher general self-efficacy scores than participants in the pre-contemplation, contemplation and preparation stages. These findings provided support for the third hypothesis.

A significant difference for stage of change in exercise was also observed in a ANOVA with the depression as the dependent variables, $F_{(4,547)}=28.05, p<0.001$. Also, as detailed in Tukey's post hoc tests indicated that participants in the pre-contemplation and contemplation stages reported higher depression scores than participants in the preparation, action and maintenance stages. These findings partially supported for the fourth hypothesis.

A significant difference for stage of change in exercise was observed in a ANOVA with psychological well-being as the dependent variables $\left(F_{(4,547)}=5.03, p<0.01\right)$. Tukey's post hoc tests indicated that participants in the pre-contemplation stage reported lower psychological well-being scores than participants in the preparation and maintenance stages. These findings provided support for the fifth hypothesis.

\section{Discussion}

This study aimed to examine the psychological factors (general self-efficacy, depression, and psychological well-being) associated with stage of change in exercise in Turkish university students. According to the findings, general 
self-efficacy and psychological well-being averages were high and depression levels were low when comparing those who exercise and those who do not. In comparison to these results, previous studies found a positive relationship between regular exercise and general self-efficacy (Fontaine \& Shaw, 1995; Yeh et al., 2011). By examining literature on the relationship between regular physical activity and depression, being physically inactive in fact does have a positive effect on depression, which supports this study's findings (Camacho, Roberts, Lazarus, Kaplan, \& Cohen, 1991; Paffenbarger, Lee \& Leung, 1994; Strawbridge, Deleger, Roberts, \& Kaplan, 2002). However, contrary to this study, several studies found no relationship between exercise and depression (Cooper-Patrick, Ford, Mead, Chang, \& Klag, 1997; Weyerer, 1992). From the point of view of psychologically well-being, many studies show that exercise has a positive effect, which supports the results of this research (Rejeski et al., 2001; Arent, Landers, \& Etnier, 2000; Lotan, Merrick \& Carmeli, 2005).

In this research, self-efficacy levels of participants in the maintenance stage of exercise behavior were higher than participants in early stages (pre-contemplation, contemplation and preparation stages). When previous studies were examined, a positively high relationship was found between self-efficacy and continuity in exercise (Marcus, Selby, Niaura, \& Rossi, 1992; Sarkin, Johnson, Prochaska \& Prochaska, 2001). Through analysing studies regarding the Trans-theoretical Model, we observed that self-efficacy levels of individuals in the pre-contemplation stage are lower than those in the contemplation stage (Armstrong, Sallis, Hovell, \& Hofstetter, 1993), while during the continuity stage self-efficacy is at the highest level (Marcus et al., 1992). This research supports the findings obtained from our study.

By considering depression, another psychological factor in our research, we observed that participants in the research group who exercise regularly and are in later exercise stages of change have lower depression points than those who are in the behavior modification of pre-contemplation stage of exercise. According to studies on the behavior modification step in exercise, depression levels are low during the advanced stages of exercise (Lee and Park, 2004; Lee, Park, \& Kim, 2006). This study's results support previous research.

In addition, psychological well-being is considered as having an effect on continuity in exercise, which has been researched in conjunction with exercise applied longitudinal studies. The result was that after 12 weeks of exercise, psychological well-being levels increased of those who continued (Scully et al., 1998; Jones et al., 2005). Since research on the notion of psychological well-being based on the behavior modification step has not been encountered in literature, our results have not been discussed in this frame.

In this study, it has been found that those who exercise and show continuity in exercise positively affects psychological phenomena like self-efficacy and psychological well-being, while not engaging in exercise or not considering exercise has a positive relation with depression. The accumulation of knowledge on this account should be helpful for practitioners working in psychological health or recreation centers in understanding university students' underlying psychological factors for continuing exercise. The study was limited to university students and it used only quantitative methods to examine psychological factors associated with exercise behavior. Another limitation can be the measure for exercise behavior, which was self-reported. Future studies are needed to use longitudinal study designs and different statistical analyses in order to draw conclusions for the potential link between psychological aspects and exercise behavior.

\section{References}

Adams, J., \& White, M. (2002). A systematic approach to the development and evaluation of an intervention promoting stair use. Health Education Journal, 61, 272-286. https://doi.org/10.1177/001789690206100308

Antunes, H. K. M., Stella, S. G., Santos, R. F., Bueno, O. F. A., \& Mello, M. T. D. (2005). Depression, anxiety and quality of life scores in seniors after an endurance exercise program. Revista Brasileira de Psiquiatria, 27, $266-271$. https://doi.org/10.1590/S1516-44462005000400003

Arent, S., Landers, M., \& Etnier, J. (2000). The effects of exercise on mood in older adults: a meta-analytic. J. Ageing Phys. Act, 8, 407-430. https://doi.org/10.1123/japa.8.4.407

Armstrong, C. A., Sallis, J. F., Hovell, M. F., \& Hofstetter, C. R. (1993). Stages of change, self-efficacy, and the adoption of vigorous exercise: A prospective analysis. Journal of Sport and Exercise Psychology, 15, 390-390. https://doi.org/10.1123/jsep.15.4.390

Bandura, A. (1977). Self-efficacy: toward a unifying theory of behavioral change. Psychological Review, 84, 191. https://doi.org/10.1037/0033-295X.84.2.191

Beck, A. T., \& Steer, R. A. (1987). Manual for the revised Beck depression inventory. San Antonio, TX: Psychological Corporation.

Bernier, M., \& Avard, J. (1986). Self-efficacy, outcome, and attrition in a weight-reduction program. Cognitive Therapy 
and Research, 10, 319-338. https://doi.org/10.1007/BF01173469

Blumenthal, J. A., Babyak, M. A., Doraiswamy, P. M., Watkins, L., Hoffman, B. M., Barbour, K. A., ... Hinderliter, A. (2007). Exercise and pharmacotherapy in the treatment of major depressive disorder. Psychosomatic Medicine, 69, 587. https://doi.org/10.1097/PSY.0b013e318148c19a

Brenes, G. A., Williamson, J. D., Messier, S. P., Rejeski, W. J., Pahor, M., I. E., \& Penninx, B. W. (2007). Treatment of minor depression in older adults: a pilot study comparing sertraline and exercise. Aging and Mental Health, 11, 61-68. https://doi.org/10.1080/13607860600736372

Burbank, P. M., Reibe, D., Padula, C. A., \& Nigg, C. (2002). Exercise and older adults: changing behavior with the Trans-theoretical model. Orthopaedic Nursing, 21, 51-63. https://doi.org/10.1097/00006416-200207000-00009

Callaghan, P., Khalil, E., Morres, I., \& Carter, T. (2011). Pragmatic randomized controlled trial of preferred intensity exercise in women living with depression. BMC Public Health, 11, 1-8. https://doi.org/10.1186/1471-2458-11-465

Camacho, T. C., Roberts, R. E., Lazarus, N. B., Kaplan, G. A., \& Cohen, R. D. (1991). Physical activity and depression: evidence from the Alameda County Study. American Journal of Epidemiology, 134, 220-231.

Cengiz, C., Aş̧̧1, F. H., \& İnce, M. L. (2010) Reliability and Validity of Physical Activity Stages of Change Questionnaire (PASCQ), Türkiye Klinikleri Journal of Sports Science, 2, 32-7.

Cooper-Patrick, L., Ford, D. E., Mead, L. A., Chang, P. P., \& Klag, M. J. (1997). Exercise and depression in midlife: a prospective study. American Journal of Public Health, 87, 670-673. https://doi.org/10.2105/AJPH.87.4.670

Department of Health. Exercise referral systems: a national quality assurance framework. (2001). http://www.dh.gov.uk/en/Publicationsandstatistics/Publications/ PublicationsPolicyAndGuidance/DH*4009671

Diener, E., Wirtz, D., Tov, W., Kim-Prieto, C., Choi, D., Oishi, S., \& Biswas-Diener, R. (2010). New well-being measures: Short scales to assess flourishing and positive and negative feelings. Social Indicators Research, 97, 143-156. https://doi.org/10.1007/s11205-009-9493-y

Donaghy, M., \& Durward B. (2000). A report on the clinical effectiveness of physiotherapy in mental health. Research and Clinical Effectiveness Unit, Chartered Society of Physiotherapy.

Fontaine, K. R., \& Shaw, D. F. (1995). Effects of self-efficacy and dispositional optimism on adherence to step aerobic exercise classes. Perceptual and Motor Skills, 81, 251-255. https://doi.org/10.2466/pms.1995.81.1.251

Fremont, J., \& Craighead, L. W. (1987). Aerobic exercise and cognitive therapy in the treatment of dysphoric moods. Cognitive Therapy and Research, 11, 241-251. https://doi.org/10.1007/BF01183268

Gelenberg, A. J. (2010). The prevalence and impact of depression. The Journal of Clinical Psychiatry, 71, 6-6. https://doi.org/10.4088/JCP.8001tx17c

Georgiadis, M., Biddle, S., \& Chatzisarantis, N. (2001). The mediating role of self-determination in the relationship between goal orientations and physical self-worth in Greek exercisers. European Journal of Sport Science, 1, 1-9. https://doi.org/10.1080/17461390100071502

Haase, A., Steptoe, A., Sallis, J. F., \& Wardle, J. (2004). Leisure-time physical activity in university students from 23 countries: associations with health beliefs, risk awareness, and national economic development. Preventive Medicine, 39, 182-190. https://doi.org/10.1016/j.ypmed.2004.01.028

Hisli, N. (1988). A study on the validity of Beck Depression Inventory. Turkish Journal of Psychology, 6(22), 118-123.

Jones, F., Harris, P., Waller, H., \& Coggins, A. (2005). Adherence to an exercise prescription scheme: the role of expectations, self-efficacy, stage of change and psychological well - being. British Journal of Health Psychology, 10, 359-378. https://doi.org/10.1348/135910704X24798

Lee, Y. M., \& Park, H. S. (2004). A study on the stage of change in exercise behaviors, exercise self-efficacy, depression and stress in middle aged women. Korean Journal of Women Health Nursing, 10, 218-225.

Lee, Y. M., Park, N. H., \& Kim, Y. H. (2006). Process of change, decisional balance, self-efficacy and depression across the stages of change for exercise among middle aged women in Korea. Taehan Kanho Hakhoe Chi, 36, 587-595.

Lotan, M., Merrick, J., \& Carmeli, E. (2005). Physical activity in adolescence. A review with clinical suggestions. International Journal of Adolescent Medicine and Health, 17, 13-22. https://doi.org/10.1515/IJAMH.2005.17.1.13

Lowther, M., Mutrie, N., \& Scott, E. M. (2007). Identifying key processes of exercise behaviour change associated with movement through the stages of exercise behaviour change. Journal of Health Psychology, 12, 261-272. https://doi.org/10.1177/1359105307074253 
Luszczynska, A., Gutiérrez-Doña, B., \& Schwarzer, R. (2005). General self - efficacy in various domains of human functioning: Evidence from five countries. International Journal of Psychology, 40, 80-89. https://doi.org/10.1080/00207590444000041

Maiolino, N., \& Kuiper, N. (2016). Examining the impact of a brief humor exercise on psychological well-being. Translational Issues in Psychological Science, 2, 4. https://doi.org/10.1037/tps0000065

Marcus, B. H., \& Lewis, B. A. (2003). Physical Activity and the Stages of Motivational Readiness for Change Model. President's Council on Physical Fitness and Sports Research Digest.

Marcus, B. H., Selby, V. C., Niaura, R. S., \& Rossi, J. S. (1992). Self-efficacy and the stages of exercise behavior change. Research quarterly for exercise and sport, 63(1), 60-66. https://doi.org/10.1080/02701367.1992.10607557

Marshall, S. J., \& Biddle, S. J. (2001). The Trans-theoretical model of behavior change: a meta-analysis of applications to physical activity and exercise. Annals of Behavioral Medicine, 23(4), 229-246. https://doi.org/10.1207/S15324796ABM2304_2

McAuley, E. (1992). The role of efficacy cognitions in the prediction of exercise behavior in middle-aged adults. Journal of Behavioral Medicine, 15, 65-88. https://doi.org/10.1007/BF00848378

McAuley, E., \& Blissmer, B. (2000). Self-efficacy determinants and consequences of physical activity. Exercise and Sport Sciences Reviews, 28, 85-88.

McAuley, E., \& Jacobson, L. (1991). Self-efficacy and exercise participation in sedentary adult females. American Journal of Health Promotion, 5, 185-207. https://doi.org/10.4278/0890-1171-5.3.185

McAuley, E., Lox, C., \& Duncan, T. E. (1993). Long-term maintenance of exercise, self-efficacy, and physiological change in older adults. Journal of Gerontology, 48, 218-224. https://doi.org/10.1093/geronj/48.4.P218

Muraven, M., \& Baumeister, R. F. (2000). Self-regulation and depletion of limited resources: Does self-control resemble a muscle? Psychological Bulletin, 126, 247-259. https://doi.org/10.1037/0033-2909.126.2.247

National Institute for Health and Clinical Excellence. Depression: the treatment and management of depression in adults (update). (2009). http://www.nice.org.uk/guidance/CG90

Network, S. I. G. (2002). Guideline 60: postnatal depression and puerperal psychosis. SIGN, Edinburgh, UK.

O'Leary, A. (1992). Self-efficacy and health: Behavioral and stress-physiological mediation. Cognitive Therapy and Research, 16, 229-245. https://doi.org/10.1007/BF01173490

Paffenbarger, R. S., Lee, I. M., \& Leung, R. (1994). Physical activity and personal characteristics associated with depression and suicide in American college men. Acta Psychiatrica Scandinavica, 89, 16-22. https://doi.org/10.1111/j.1600-0447.1994.tb05796.x

Prochaska, J. O., \& DiClemente, C. C. (1984). The Trans-theoretical approach: Crossing traditional boundaries of therapy. Pacific Grove, CA: Brooks/Cole.

Prochaska, J. O., \& Velicer, W. F. (1997). The Trans-theoretical model of health behavior change. American Journal of Health Promotion, 12, 38-48. https://doi.org/10.4278/0890-1171-12.1.38

Purath, J., Michaels Miller, A., McCabe, G., \& Wilbur, J. (2004). A Brief Intervention to Increase Physical Activity in Sedentary Working Women Une intervention ponctuelle en vue d'accroître l'activité physique chez les travailleuses sédentaires. CJNR (Canadian Journal of Nursing Research), 36, 76-91.

Rejeski, W. J., Shelton, B., Miller, M., Dunn, A. L., King, A. C., Sallis, J. F., \& Activity Counseling Trial Research Group. (2001). Mediators of increased physical activity and change in subjective well-being: Results from the Activity Counseling Trial (ACT). Journal of Health Psychology, 6, 159-168. https://doi.org/10.1177/135910530100600206

Rodgers, W. M., Hall, C. R., Duncan, L. R., Pearson, E., \& Milne, M. I. (2010). Becoming a regular exerciser: Examining change in behavioural regulations among exercise initiates. Psychology of Sport and Exercise, 11, 378-386. https://doi.org/10.1016/j.psychsport.2010.04.007

Sarkin, J. A., Johnson, S. S., Prochaska, J. O., \& Prochaska, J. M. (2001). Applying the Trans-theoretical model to regular moderate exercise in an overweight population: validation of a stages of change measure. Preventive Medicine, 33, 462-469. https://doi.org/10.1006/pmed.2001.0916

Savcı, S., Öztürk, M., Arıkan, H., İnal İnce, D., \& Tokgözoğlu, L. (2006). Physical activity level of University students. Türk Kardiyoloji Arşivi, 34, 166-172. 
Scully, D., Kremer, J., Meade, M. M., Graham, R., \& Dudgeon, K. (1998). Physical exercise and psychological well-being: a critical review. British Journal of Sports Medicine, 32, 111-120. https://doi.org/10.1136/bjsm.32.2.111

Sebire, S. J., Standage, M., \& Vansteenkiste, M. (2009). Examining intrinsic versus extrinsic exercise goals: Cognitive, affective, and behavioral outcomes. Journal of Sport and exercise Psychology, 31, 189-210. https://doi.org/10.1123/jsep.31.2.189

Sebire, S. J., Standage, M., \& Vansteenkiste, M. (2011). Predicting objectively assessed physical activity from the content and regulation of exercise goals: evidence for a mediational model. Journal of Sport \& Exercise Psychology, 33, 175-197. https://doi.org/10.1123/jsep.33.2.175

Sherer, M., \& Adams, C. H. (1983). Construct validation of the self-efficacy scale. Psychological Reports, 53, 899-902. https://doi.org/10.2466/pr0.1983.53.3.899

Singh, N. A., Clements, K. M., \& Singh, M. A. F. (2001). The efficacy of exercise as a long-term antidepressant in elderly subjects a randomized, controlled trial. The Journals of Gerontology Series A: Biological Sciences and Medical Sciences, 56, 497-504. https://doi.org/10.1093/gerona/56.8.M497

Sorensen JB, Skovgaard T, Puggaard L. (2006). Exercise on prescription in general practice: a systematic review. Scandinavian Journal of Primary Health Care; 24, 69-74. https://doi.org/10.1080/02813430600700027

Spencer, L., Adams, T. B., Malone, S., Roy, L., \& Yost, E. (2006). Applying the Trans-theoretical model to exercise: a systematic and comprehensive review of the literature. Health Promotion Practice, 7, 428-443. https://doi.org/10.1177/1524839905278900

Strawbridge, W. J., Deleger, S., Roberts, R. E., \& Kaplan, G. A. (2002). Physical activity reduces the risk of subsequent depression for older adults. American Journal of Epidemiology, 156, 328-334. https://doi.org/10.1093/aje/kwf047

Telef, B. B. (2013). The Adaptation of Psychological Well-Being into Turkish: A Validity and Reliability Study, Hacettepe Üniversitesi Ĕgitim Fakültesi Dergisi, 28, 374-384.

Thøgersen-Ntoumani, C., \& Ntoumanis, N. (2006). The role of self-determined motivation in the understanding of exercise-related behaviours, cognitions and physical self-evaluations. Journal of Sports Sciences, 24, 393-404. https://doi.org/10.1080/02640410500131670

United States. Department of Health, \& Human Services. (1996). Physical activity and health: A report of the Surgeon General. Diane Publishing.

Weyerer, S. (1992). Physical inactivity and depression in the community. International Journal of Sports Medicine, 13, 492-496. https://doi.org/10.1055/s-2007-1021304

WHOQOL group. (1995). The World Health Organization quality of life assessment (WHOQOL): position paper from the World Health Organization. Social Science \& Medicine, 41, 1403-1409. https://doi.org/10.1016/0277-9536(95)00112-K

Woods, C., Mutrie, N., \& Scott, M. (2002). Physical activity intervention: a Trans-theoretical model-based intervention designed to help sedentary young adults become active. Health Education Research, 17, 451-460. https://doi.org/10.1093/her/17.4.451

Yeh, G. Y., McCarthy, E. P., Wayne, P. M., Stevenson, L. W., Wood, M. J., Forman, D., ... \& Phillips, R. S. (2011). Tai chi exercise in patients with chronic heart failure: a randomized clinical trial. Archives of Internal Medicine, 171, 750-757. https://doi.org/10.1001/archinternmed.2011.150

Yildirim, F., \& İlhan, İ. Ö. (2010). Validity and Reliability Study of the Turkish Form of the General Self-efficacy Scale. Türk Psikiyatri Dergisi, 21, 301-308.

\section{Copyrights}

Copyright for this article is retained by the author(s), with first publication rights granted to the journal.

This is an open-access article distributed under the terms and conditions of the Creative Commons Attribution license which permits unrestricted use, distribution, and reproduction in any medium, provided the original work is properly cited. 